\title{
Assessment of Nutritional Practices of Pregnant Mothers on Maternal Nutrition and Associated Factors in Guto Gida Woreda, East Wollega Zone, Ethiopia
}

\author{
Gemeda Daba*, Fekadu Beyene, Wondu Garoma and Habtamu Fekadu \\ Department of Nutrition and Food Science, College of Engineering and Technology, Wollega University, \\ Post Box No: 395, Nekemte, Ethiopia
}

\begin{abstract}
Nutrition is a fundamental pillar of human life, health and development throughout the entire life span. The nutrition requirement varies with respect to age, gender and during physiological changes such as pregnancy. Pregnancy is a critical phase in a woman's life, when the expectant mother needs optimal nutrients of superior food qualities to support the developing fetus. The aim of this study was to assess the practices of pregnant mothers on maternal nutrition and associated factors in Guto Gida Woreda, East Wollega Zone, Ethiopia. The study was conducted during January to June of the year 2013, using quantitative cross-sectional descriptive study on a sample of 422 pregnant women and supplemented by qualitative study (focus group discussion). The quantitative data were analyzed using SPSS for windows version (16.0). Multiple logistic regression was run to assess factors that were associated with the dependent variable at $P<0.05$ and to control the confounders. Finally, the result of the study was presented using narratives and tables. This research showed only $33.9 \%$ of the respondents were found to have good nutritional practices during their pregnancy. There was a positive significant relation between information about nutrition and family size and nutritional practices of mothers during pregnancy $(P<0.001)$. The practices of pregnant mothers about maternal nutrition were relatively low in this study. Information about nutrition and family size of mothers had a positive significant relation with mothers' nutrition practices in the study area. Hence, the government in collaboration with concerned bodies should focus on nutritional education and information about nutrition to increase the practices of pregnant mothers on maternal nutrition during pregnancy in the study area.
\end{abstract}

\author{
Article Information \\ Article History: \\ Received : 19-08-2013 \\ Revised : 25-09-2013 \\ Accepted : 28-09-2013
}

Keywords:

Practices

Maternal nutrition

Pregnancy

Guto Gida Woreda

Ethiopia

${ }^{*}$ Corresponding Author:

Gemeda Daba

E-mail:

Gamedb2012@gmail.com

\section{INTRODUCTION}

All human beings need a balanced amount of nutrients for proper functioning of the body system. Nutrition is a fundamental pillar of human life, health and development throughout the entire life span (World Bank, 2006). Proper food and good nutrition are essential for survival, physical growth, mental development, performance and productivity, health and wellbeing. However, the nutrition requirement varies with respect to age, gender and during physiological changes such as pregnancy. Pregnancy is such a critical phase in a woman's life, when the expecting mother needs optimal nutrients of superior qualities to support the developing fetus.
Naturally, the urge to eat more is experienced by nearly all pregnant women (World Bank, 2006).

Nutrition throughout life has a major effect on health. This is true for pregnant women as adequate maternal nutrition is one of the best ways to ensure maternal and fetal wellbeing in developed and developing countries. A mother's nutritional status at conception, during pregnancy and lactation, plays a key role in determining her health and well-being, as well as that of her child. So does the quality and quantity of her diet. Providing a nourishing diet for pregnant and lactating women therefore results in 


\section{Gemeda Daba et al.,}

significantly better infant health outcomes. Recent evidence suggests that it may also reduce the risk of chronic diseases later in life. During pregnancy and breast-feeding, the recommended intakes for most nutrients increase (Barker et al., 1993).

Pregnancy is considered to be a delightful experience for the expectant mother. However, feeling of well being and quality of life outcomes, as significant determinate of health, were shown to decline in some dimensions during pregnancy (Nicholson et al., 2006). Studies demonstrated that emotional, physical functioning, vitality and social functioning as dimensions of life quality were inconsistent in different phases of pregnancy (Otchet et al., 1999).

Furthermore, evidences manifested that adequate intake of nutrition is a key component for individual's health and well-being, particularly during pregnancy. It is well documented that inadequate maternal nutrition results in increased risks of short term consequences such as; Intra Uterine Growth Restriction(IUGR), low birth weight, preterm birth, prenatal and infant mortality and morbidity. Moreover, excessive intake of nutrients during pregnancy can lead to some pregnancy complications (such as, preeclampsia and gestational diabetes, macrosomia, distocia and higher prevalence of cesarean section) (Luigi et al., 2005). On the other hand, as the long run outcomes, inadequate intake of nutrients were found to have pathophysiologic or metabolic depict that will appear as disorders of child growth and development as well as adult chronic disease after a long period of quiescence (Luigi et al., 2005).

Eating well during pregnancy means do more than simply increase how much the mother eats. The mother must also consider what she eats. The ability of mother to provide nutrients and oxygen for her baby is a critical factor for fetal health and its survival. Failure in supplying the adequate amount of nutrients to meet fetal demand can lead to fetal malnutrition. The fetus responds and adapts to under nutrition but by doing so it permanently alters the structure and function of the body. Maternal over nutrition also has long-lasting and detrimental effects on the health of the offspring (Maynord et al., 2003).

Malnutrition is one of the most serious health problems affecting children and their mothers in Ethiopia. Undernourished mothers face greater risks during pregnancy and childbirth, and their children set off on a weaker developmental path, both physically and mentally. Undernourished children have lower resistance to infection and are more likely to die from common childhood ailments as
Sci. Technol. Arts Res. J., July-Sep 2013, 2(3): 105-113

diarrheal diseases and respiratory infections. Those who survive may be locked into a vicious cycle of recurring sickness and faltering growth, often with irreversible damage to their cognitive and social development. Malnutrition prevents individuals and even the whole country from achieving full potential, and is closely related with survival, poverty and development (IYCN, 2011).

Several study including Villar et al., (2003) has indicated that the correlation between poor maternal nutritional status and adverse birth outcomes is complex and are influenced by many biologic, socioeconomic, and demographic factors, which vary widely in different populations (Villar et al., 2003).

It is therefore, the promotion of women's health and other preventive health care practice should start before birth, during intrauterine life and extends throughout different phases of their lives in order to sustain their reproductive health in general. The importance of maternal nutrition during pregnancy has long been recognized. The National Academy of Science in America issued a report that reviewed studies of reproductive experience concluded that adequate prenatal nutrition was one of the most important environmental factors affecting the health of pregnant women and their babies (Nagiebs, 2003).

According to UNICEF (2009), each year, more than half a million women die from causes related to pregnancy and childbirth. Nearly 4 million newborns die within 28 days of birth. The lifetime risk of maternal death for a woman in a least developed country is more than 300 times greater than for a woman living in an industrialized country (UNICEF, 2009).

More than $40 \%$ of pregnancies in developing countries result in complications, illness, or permanent disability for the mother or child (Tinker et al., 1994). More than 7 million newborn deaths are associated with maternal health- and nutrition related problems resulting from poorly managed pregnancies and deliveries or inadequate care of the neonate soon after birth (WHO, 1997).

Many of the 200 million women who become pregnant each year, most of them in developing countries (WHO, 1997), suffer from ongoing nutritional deficiencies (Mora and Nestel, 2000), repeated infections (Wu et al., 2004) and the long term cumulative consequences of under nutrition during their own childhood (Mora and Nestel, 2000).

Maternal under-nutrition affects the health of both mothers and children and, as a result, has broad 
Gemeda Daba et al.,

impacts on economic and social development. Undernourished pregnant women have higher reproductive risks, including death during or following child birth. Many women suffer from a combination of chronic energy deficiency, poor weight gain in pregnancy, anemia, and other micronutrient deficiencies, as well as infections like HIV and malaria. These along with inadequate obstetric care, contribute to high rates of maternal mortality and poor birth outcomes (Huffman et al., 2001 and AED LINKAGES, 2004).

Under-nutrition in pregnant women is directly linked to intrauterine growth retardation (IUGR), which results in low birth weight, pre-maturity, and low nutrient stores in infants. Maternal undernutrition also diminishes a woman's productivity, causing repercussions for herself, her family, her community, and the broader society. Maternal malnutrition is influenced not only by lack of adequate nutrition but also influenced by factors like socio demographic factors, knowledge of mothers, attitude and practice of mothers during pregnancies (AED LINKAGES, 2004).

Although, researches and projects focused on maternal health are common, projects and researches focused specifically on maternal nutrition are rare (Huffman et al., 2001) in the study area. Research, program reports, and other materials specifically related to maternal nutrition principles, practices, and programs are not abundant either (Huffman et al., 2001). This lack of attention to maternal nutrition may in part reflect a focus on mortality reduction rather than on growth and development.

Even though maternal nutrition during pregnancy is crucial in reducing maternal mortality and infant mortality which are the target area in achieving millennium development goal, no study has been conducted the assessment of practices of mothers on nutrition and factors affecting it during pregnancy in the study area. As a result, there is lack of comprehensive information regarding practices and the factors associated with them in the study area. So, of the study was to assess the practices of pregnant mothers on maternal nutrition and associated factors in Guto Gida Woreda, East Wollega Zone, Ethiopia.

\section{MATERIALS AND METHODS}

\section{Study Setting}

A cross-sectional descriptive institutional based study was conducted to assess practices of pregnant women about maternal nutrition and associated factors that employed both quantitative and qualitative data collection method during
Sci. Technol. Arts Res. J., July-Sep 2013, 2(3): 105-113

January to June of the year 2013 in Guto Gida Woreda, East Wollega zone, Ethiopia. Guto Gida Woreda has a total area of $901.80 \mathrm{~km}^{2}$ and crude population density of 115.43 persons per $\mathrm{km}^{2}$ as the 2004 E.C.data record indicated and divided in to 21 farmers associations and one urban center.

According to the information from Guto Gida Woreda health office (population and housing census conducted in 2007 G.C), the total population in the woreda was 105,332 in 2005 E.C out of which $97.22 \%$ of the total populations were living in rural area directly engaged their life agriculture and the total numbers of pregnant women were about $3897(3.7 \%)$ in the same year.

Furthermore, according to the information from Guto Gida Woreda health office during data collection there were two health centers and 24 health posts under government ownership providing health services for the community in the woreda.

\section{Source Population}

All Pregnant women who visited Guto Gida health centers and health posts antenatal care fellow up during January to June of the year 2013.

\section{Study Population}

Sampled pregnant women who visited Guto Gida health centers and health posts for antenatal care during January to June of the year 2013.

\section{Sample Size Determination Quantitative Method}

The sample size was determined by the assumption that $50 \%$ of the pregnant mothers had bad practices on maternal nutrition during pregnancy with $5 \%$ marginal error and $95 \% \mathrm{Cl}$ and a none response rate of $10 \%$. Based on this assumption, the actual sample size for the study was determined using the formula for single population proportion.

$$
\mathrm{n}=\frac{\left(\mathrm{Z}_{\frac{\alpha}{2}}\right)^{2} \mathrm{pq}}{\mathrm{d}^{2}}
$$

Where $\mathrm{n}=$ Sample size

$Z_{\alpha / 2}=Z$ value corresponding to a $95 \%$ level of significance $=1.96$

$\mathrm{p}=$ expected proportion of practices of mothers on nutrition during pregnancy $=50 \%=0.5$

$q=(1-p)=(1-0.5)=0.5$

$\mathrm{d}=$ absolute precision $(5 \%)$

None response rate $=10 \%$

Therefore, from the above sample size is:

$\mathrm{n}=\frac{1.96^{2} \times 0.5 \times 0.5}{0.05 \times 0.05}$

$$
0.05 \times 0.05
$$

$$
\mathrm{n}=384+38=422
$$

\section{Qualitative Method}

For the qualitative study focus group discussion (FGD) was carried out by purposively selected 
Gemeda Daba et al.,

groups of pregnant women that were not participated in the quantitative study from the same areas.

\section{Sampling Procedure}

The calculated sample size was proportionally allocated to the randomly selected health center and health posts from Guto Gida Woreda based on the average number of client prior to the study period in the respective antenatal care fellow units. Then to select study subjects from each antenatal care unit, systematic sampling was applied by referring client's registration book for a month prior to data collection. It was from these numbers that every $k^{\text {th }}$ person as they registered was included in the sample at each antenatal care unit until the desired sample size was obtained.

\section{Data Collection Procedures}

Semi-structured questionnaires prepared in English language were translated in to Afan Oromo and then translated back to English to check for consistency. In addition, focus group discussions were used for the qualitative study.

\section{Pre-testing Questionnaire}

The semi-structured questionnaires were pretested in Nekemte health center antenatal care unit. The pre-test were done on $5 \%$ of the total sample size. The questionnaire was then assessed for its clarity, length and completeness. Some skip patterns were then corrected; questions difficult to ask were rephrased.

\section{Data Collection}

\section{Quantitative Data}

For administering the semi-structured questionnaire, four heath professionals who had diploma were recruited to conduct an interview. Training was given for two days (including half day of pretest) on the objective, relevance of the study, confidentiality of information, respondent's right, informed consent and techniques of interview. Moreover, class room practical demonstration of the interview was also carried out. One supervisor who has fist degree was assigned to supervise the data collection.

\section{Qualitative Data}

To compliment the quantitative study, focus group discussions at two sites were carried out with each participating six members of pregnant women along with principal investigator. Finally, the information was tape recorded to support the field notes used during discussion.
Sci. Technol. Arts Res. J., July-Sep 2013, 2(3): 105-113

\section{Variables \\ Dependent Variable}

practices of pregnant mothers about maternal nutrition

\section{Practices of Pregnant Mothers about Nutrition}

Under the construct of nutritional practices of pregnant mothers, there were seven questions for quantitative study. Nutrition practices questions aimed in assessing nutrition practices of pregnant women towards the nutrition required and dietary practices during pregnancy. Pregnant women were asked about their dietary practices.

- The habit of eating more carbohydrates between meals

- If they experience any problems that are interfering with their day to day food intake

- If they avoid any food or diet in the current pregnancy

- The current diet frequency of meal per day

- The habit of eating more snacks between meals during pregnancy

- If they follow there weight during pregnancy

- If they face any cravings for items that you would normally not consume

The respondents had asked to choose yes or no answers by indicating whether a given statement was there dietary practices or not by allowing them to list or state how they practiced for those correctly answered respondents to explore how much they practiced about what they responded correctly with open ended questions. To determine nutrition practice level of the respondents, scores were computed for the nutrition practices variables. One point was allocated to a correct response for each questions of nutrition practices in which the correct answers summed together (the sum of the total scores for nutrition practices varied from ( 0 up to 7 ) points maximum score) and converted out of 100.

Independent (determinant) Variable

- Socio-demographic characteristics

- Nutrition information and residence of the respondents

- Pre pregnancy nutritional status, health conditions, number of pregnancies before the current pregnancy and the space/gap between pregnancies

\section{Data Quality Assurance}

To ensure the quality of data, training of data collectors and supervisors were undertaken and administration of pre-test among $5 \%$ of the total sample size to assessed its clarity, length, completeness and consistency. The questionnaires were also translated in to local language to facilitate understanding of the respondents. 
Gemeda Daba et al.,

Supervisors and principal investigator closely followed the data collection process. Filed questionnaires were checked daily for completeness and errors were corrected. In addition to written documentation of responses from study participants, tape recording were done after obtaining verbal consent to ensure that all feedback are captured for analysis.

\section{Data Analysis}

The data were cheeked, cleared and entered into SPSS data sheet software and analysis was done by using SPSS version (16.0). The descriptive analysis such as proportions, percentages, frequency distribution and measures of central tendency were used.

Initially, bivariable analysis was performed between practices of mothers on maternal nutrition during pregnancy (dependent variable) and each of the potential factors associated with practices of mothers on nutrition during pregnancy (independent variables), one at a time. Their odds ratios (OR) at 95\% confidence intervals $(\mathrm{Cl})$ and p-values was obtained. The findings at this stage helped us to identify important associations.

Then multivariable analysis was performed using the logistic regression model. Factors that are significantly associated with practices of mothers on nutrition during pregnancy at bivariate analysis and those not significant but with previous evidence from literature review indicating possible association with practices of mothers on nutrition during pregnancy was considered in multivariate logistic regression model.

\section{Ethical Considerations}

Ethical clearance and permission were obtained from Wollega University Ethical Review Committee and permission was secured from Guto Gida Woreda health office. The nature of the study was fully explained to the study participants to obtain their oral informed consent prior to participation in the study and data was kept confidential.

\section{RESULTS}

\section{Socio-demographic characteristics}

Out of the 422 sampled pregnant women to be included in this study 419 responded to the questionnaires making a response rate of $99.3 \%$. Different questions were asked to assess practices of pregnant mothers on maternal nutrition and determinant factors in the study area. The mean age (+/-SD) of the participants was $24.7(+/-5.12)$ years, while the age range was 16-38. However, considerably high proportions of the respondents $(48.2 \%)$ were in the age range of $15-24$ years.
Sci. Technol. Arts Res. J., July-Sep 2013, 2(3): 105-113

Besides, most study respondents were married (97.1\%).

Regarding the ethnic composition and religion of the respondents about greater than three quarter of them were Oromo and the majority of respondents' religion was protestant followed by Orthodox as shown in the table 1.

As far as education level of study population is concerned, almost two third $(65.4 \%)$ of the respondents were illiterate. Concerning the occupation of respondents, the majority (85.7\%) were house wives. Greater than three quarter $(89.8 \%)$ of the respondents husbands occupation were farmer, whom above half $(52 \%)$ of their educational status were illiterate as described in table 1.

On the other way regarding women's estimated monthly income majority of women(79.0\%) earned less than 1000 birr per month, $(10.0 \%)$ of them earned $1000-2000$ birr per month and only $(11.0 \%)$ of the respondents had monthly income greater than 2000birr.

As far as residence and nutrition information during pregnancy are concerned, about $(95.7 \%)$ of the respondents were living in rural and only less than half of the respondents $(42.2 \%)$ had no nutritional information during their pregnancy as here presented in table 1.

On the other hand, twelve pregnant women participated in focus group discussion for qualitative study. Their age ranges from 20-35 years. Most respondents were married while ten of them were house wife. Eight of the respondents were illiterate while four of them had attended at least primary education.

\section{Practice of Mothers On Nutrition During Pregnancy}

Out of 419 study participants responded to the questions assessing nutritional practices, less than half $(47 \%)$ of respondents had experienced any craving for items that they would not normally consume but most $(53 \%)$ of the study participants had not experienced any craving for items that they would not normally consume as indicated in table.

Regarding avoidance of any food during pregnancy, only $(35.8 \%)$ of the respondents had practiced avoiding food during their pregnancy. Out of those who avoided food during their pregnancy, $(46.7 \%)$ reported makes the baby big, $(36.0 \%)$ reported cultures, $(14.7 \%)$ reported makes delivery difficult and $(2.6 \%)$ reported religions as the reason for avoidance of the food respectively. But (64.2\%) of the respondents had not avoided any food item during their pregnancy. 
Gemeda Daba et al.,

Table 1: Socio-demographic characteristics of study participants.

\begin{tabular}{|c|c|}
\hline Characteristics $(n=419)$ & Number (\%) \\
\hline $\begin{array}{r}\text { Age } \\
15-24 \\
25-34 \\
35-44 \\
44+\end{array}$ & $\begin{array}{c}202(48.2) \\
188(44.9) \\
29(6.9) \\
0(0.0)\end{array}$ \\
\hline $\begin{array}{c}\text { Marital status } \\
\text { Married } \\
\text { Divorced } \\
\text { Widowed }\end{array}$ & $\begin{array}{c}407(97.1) \\
3(0.7) \\
9(2.2)\end{array}$ \\
\hline $\begin{array}{c}\text { Ethnicity } \\
\text { Oromo } \\
\text { Amahara } \\
\text { Tigre } \\
\end{array}$ & $\begin{array}{c}348(83.1) \\
55(13.1) \\
16(3.8)\end{array}$ \\
\hline $\begin{array}{l}\text { Religion } \\
\text { Orthodox } \\
\text { Catholic } \\
\text { Muslim } \\
\text { Protestant } \\
\end{array}$ & $\begin{array}{c}156(37.2) \\
0(0.0) \\
39(9.3) \\
224(53.5) \\
\end{array}$ \\
\hline $\begin{array}{l}\text { Educational Status } \\
\text { Illiterate } \\
\text { Primary }(1-8) \\
\text { Secondary(9-12) } \\
\text { Diploma and above }\end{array}$ & $\begin{array}{c}274(65.4) \\
105(25.1) \\
39(9.3) \\
1(0.2) \\
\end{array}$ \\
\hline $\begin{array}{l}\text { Occupational Status } \\
\text { Employed } \\
\text { House wife } \\
\text { Daily laborers } \\
\text { Business } \\
\end{array}$ & $\begin{array}{c}8(1.9) \\
359(85.7) \\
22(5.3) \\
30(7.2) \\
\end{array}$ \\
\hline $\begin{array}{l}\text { Estimated monthly } \\
\text { respondents income (in Eth. } \\
\begin{array}{ll}\text { Birr) } & <1000 \\
& 1000-2000 \\
& >2000 \\
& \end{array} \\
\end{array}$ & $\begin{array}{c}331(79.0) \\
42(10.0) \\
46(11.0)\end{array}$ \\
\hline $\begin{array}{l}\text { Respondents Husband } \\
\text { Occupation } \\
\text { Employed } \\
\text { Business } \\
\text { Farmer } \\
\end{array}$ & $\begin{array}{c}6(1.4) \\
37(8.8) \\
376(89.8)\end{array}$ \\
\hline $\begin{array}{l}\text { Respondents access } \\
\text { to information about } \\
\text { nutrition during pregnancy } \\
\text { Yes } \\
\text { No } \\
\end{array}$ & $\begin{array}{l}242(57.8) \\
177(42.2)\end{array}$ \\
\hline
\end{tabular}

As indicated in the table 2, (59.9\%) and $(70.9 \%)$ of the respondents did not practiced the habit of eating snacks and carbohydrates between meals during their pregnancy respectively. But $(40.1 \%)$ and $(29.1 \%)$ of the respondents had the practice of eating snacks and carbohydrate respectively between meals during their pregnancy for the nutritional practice assessing question.

Concerning the diet frequency of meal per day, most of the respondents $(66.1 \%)$ had diet frequency of meal 1-2 per day during their pregnancy. The rest $(20.3 \%)$ and $(13.6 \%)$ had diet frequency of meals 3-
Sci. Technol. Arts Res. J., July-Sep 2013, 2(3): 105-113

4 and $\geq 5$ per day respectively during their pregnancy for the nutritional practice assessing question.

Most of the respondent (76.6\%) had practiced in following their weight during pregnancy where as the rest $(23.4 \%)$ of the respondent had not practiced in weight fellow during their pregnancy as shown in the table 2 below.

Table 2: Practice characteristics of study participants of pregnant women on maternal nurtition

\begin{tabular}{|c|c|}
\hline Characteristics & Number (\%) \\
\hline $\begin{array}{l}\text { Facing any cravings for items that you } \\
\text { would normally not consume }(n=419) \\
\text { yes } \\
\text { no }\end{array}$ & $\begin{array}{l}197(47.0) \\
222(53.0)\end{array}$ \\
\hline $\begin{array}{l}\text { Do you avoid any food or diet in the } \\
\text { current pregnancy? }(n=419) \\
\text { yes } \\
\text { no }\end{array}$ & $\begin{array}{l}150(35.8) \\
269(64.2)\end{array}$ \\
\hline $\begin{array}{l}\text { Reason of avoidance of any food or } \\
\text { diet in the current pregnancy? }(n=150) \\
\text { Religion } \\
\text { Culture } \\
\text { Make the baby big } \\
\text { Makes delivery difficult }\end{array}$ & $\begin{array}{l}4(2.6) \\
54(36.0) \\
70(46.7) \\
22(14.7)\end{array}$ \\
\hline $\begin{array}{l}\text { What is your current diet frequency of } \\
\text { meal per day? }(n=419) \\
\qquad \begin{array}{c}1-2 \\
3-4 \\
\geq 5\end{array}\end{array}$ & $\begin{array}{l}277(66.1) \\
85(20.3) \\
57(13.6)\end{array}$ \\
\hline $\begin{array}{l}\text { The habits of eating snacks between } \\
\text { meals during pregnancy }(\mathbf{n}=419) \\
\text { yes } \\
\text { no }\end{array}$ & $\begin{array}{l}168(40.1) \\
251(59.9)\end{array}$ \\
\hline $\begin{array}{l}\text { Do you have the habit of eating more } \\
\text { carbohydrate between meals during } \\
\text { pregnancy? }(n=419) \\
\text { Yes } \\
\text { No }\end{array}$ & $\begin{array}{l}122(29.1) \\
297(70.9)\end{array}$ \\
\hline $\begin{array}{l}\text { Do you follow your weight during } \\
\text { pregnancy? }(n=419) \\
\text { Yes } \\
\text { No }\end{array}$ & $\begin{array}{l}321(76.6 \%) \\
98(23.8 \%)\end{array}$ \\
\hline
\end{tabular}

In general, $33.9 \%$ of the respondents were found to have good practice depending up on questions offered to them to assess practices of mothers' maternal nutrition during their pregnancy.

\section{Factors Affecting Mothers' Nutrition Practices During Pregnancy}

Previous number of pregnancy, mothers occupation and residence of the respondent have significant association with practices of mothers on nutrition during their pregnancy $(P<0.05)$. Moreover, in bivariate analysis, information about nutrition and family size of the respondents have strong statistical 


\section{Gemeda Daba et al.,}

association with good practices of mothers on nutrition during their pregnancy $(P<0.001)$. whereas, age, educational level of mothers, income, husbands educational level and pregnancy health problems have no association with practices of mothers on nutrition $(P>0.05)$.

In a multivariable analysis residence of the respondent and mothers occupation were displayed significant positive relationships with a woman's odds of nutrition practices during pregnancy $(P<0.01)$. Relative to employed women, daily laborer women had significantly less odds of practices on nutrition during pregnancy $(A O R=$ $0.009,95 \% \mathrm{Cl}: 0.001-0.170)$ as here presented in the table 3 below.
Sci. Technol. Arts Res. J., July-Sep 2013, 2(3): 105-113

From further multivariable analysis, the finding of the study identified that family size have strong statistical association with nutrition practices of mothers during pregnancy $(P<0.001)$. Relative to the pregnant women with family size of $1-2$, women with family size of $\geq 5$ had 0.04 less likely nutrition practices during pregnancy $(\mathrm{AOR}=0.04,95 \% \mathrm{Cl}$ : $0.01-0.15)$. In addition the finding revealed that information about nutrition during pregnancy have strong statistical association with practices of mothers on nutrition $(P<0.001)$.Women who had information about nutrition during pregnancy had 6.3 more likely good nutrition practice than women who had no information during pregnancy $(\mathrm{AOR}=6.26$, $95 \% \mathrm{Cl}: 3.49-11.25)$ as shown in table 3.

Table 3: Multivariable of nutrition practices by socio-demographic of study participants.

\begin{tabular}{|c|c|c|c|c|}
\hline \multirow[t]{2}{*}{ Variables } & \multicolumn{2}{|c|}{ Practice } & \multicolumn{2}{|c|}{$95 \% \mathrm{Cl}$} \\
\hline & Good & Poor & COR & AOR \\
\hline \multicolumn{5}{|l|}{ Family size } \\
\hline$\leq 2$ & $94(43.7)$ & $121(56.3)$ & 1 & 1 \\
\hline$\overline{3}-4$ & $31(22.8)$ & $105(77.2)$ & $0.380\left(0.234-0.616^{* * *}\right.$ & $0.107(0.046-0.251)^{\star * *}$ \\
\hline$\geq 5$ & $17(25.0)$ & $51(75.0)$ & $0.429(0.233-0.791)^{\star *}$ & $0.039(0.010-0.151)^{* * *}$ \\
\hline \multicolumn{5}{|c|}{ Information about Nutrition } \\
\hline No & $38(21.5)$ & 139(78.5) & 1 & 1 \\
\hline Yes & $104(43.0)$ & $138(57.0)$ & $2.757(1.776-4.280)^{\star \star *}$ & $6.264(3.487-11.254)^{\star \star *}$ \\
\hline \multicolumn{5}{|c|}{$\begin{array}{l}\text { No of pregnancy before the } \\
\text { current pregnancy }\end{array}$} \\
\hline$\leq 2$ & $85(36.0)$ & $151(64.0)$ & 1 & 1 \\
\hline $3-4$ & $26(22.4)$ & $90(77.6)$ & $0.513(0.308-0.855)^{*}$ & $3.537(1.492-8.386)$ \\
\hline$\geq 5$ & $31(46.3)$ & $36(53.7)$ & $1.530(0.844-2.648)$ & $26.238(7.015-98.138)$ \\
\hline \multicolumn{5}{|l|}{ Residence } \\
\hline Urban & $1(5.6)$ & $17(94.4)$ & 1 & 1 \\
\hline Rural & $141(35.2)$ & $260(64.8)$ & $9.219(1.214-69.998)^{*}$ & $49.730(4.668-529.825)^{\star *}$ \\
\hline \multicolumn{5}{|l|}{ Mothers Occupation } \\
\hline Employed & $7(87.5)$ & $1(12.5)$ & 1 & 1 \\
\hline Business & $12(40.0)$ & $18(60.0)$ & $0.095(0.010-0.876)^{*}$ & $0.040(0.002-0.692)^{*}$ \\
\hline Housewife & $117(32.6)$ & $242(67.4)$ & $0.069(0.008-0.568)^{*}$ & $0.037(0.003-0.531)^{*}$ \\
\hline Daily laborer & $6(27.3)$ & $16(72.7)$ & $0.054(0.005-0.532)^{*}$ & $0.009(0.001-0.170)^{\star *}$ \\
\hline
\end{tabular}

\section{DISCUSSIONS}

This study has documented the level of practice of mothers during pregnancy on maternal nutrition and associated factors in Guto Gida Woreda, East Wollega zone, Ethiopia. The incidence of dietary inadequacies as a result of dietary habits and patterns in pregnancy is higher during pregnancy than at any other stage of the life cycle (Rao et al., 2006).

This study showed that $(35.8 \%)$ of the respondents had practiced avoiding food during their pregnancy. Out of those who avoided food during their pregnancy, $(46.7 \%)$ reported that it makes the baby big: type of food they mentioned were fat, banana, $(36.0 \%)$ reported cultures: type of food they mentioned were porridge, red meat etc. $(14.7 \%)$ reported makes delivery difficult and $(2.6 \%)$ reported religions as the reason for avoidance of the food respectively. This figure is lower than the study conducted in Accra, Ghana by Alice et al.,(2012) in which nearly half $(44.8 \%)$ of the pregnant women in the study avoided at least one kind of food. This discrepancy may be due to difference in the culture, religion and socio economic back ground of study participants of the studies.

This study revealed that (47\%) respondents had experienced any craving for items that they would not normally consume which is much lower than the one studied in southern Ethiopia by Tsegaye Demissie et al. (1996) in which slightly fewer than three-quarters $(71 \%)$ of the women craved one or more foods during pregnancy. This difference may be due to the difference agricultural products as food staffs availability in the study areas. 


\section{Gemeda Daba et al.,}

This study showed that more than half $(59.9 \%)$ of the respondents did not practiced the habit of eating snacks between meals during their pregnancy which is different from the study conducted in Accra, Ghana, that revealed the frequency of snack consumption per day increased during pregnancy. Different types of snacks were consumed before and during pregnancy. Snacks consumed included pastries, fruits, fruit juices or fizzy drinks, roasted plantain and groundnut and ice cream (Alice et al., 2012).

This study showed that the diet frequency of meal per day: most of the respondents $(66.1 \%)$ had diet frequency of meal 1-2 per day during their pregnancy. The rest $(20.3 \%)$ and $(13.6 \%)$ had diet frequency of meals $3-4$ and $\geq 5$ per day respectively during their pregnancy. The figure resulted by this study about frequency meal consumption of greater than three per day is lower than the study conducted in Accra, Ghana, that a greater proportion $(37.7 \%)$ of the women are more than three times during pregnancy as compared to only $11.5 \%$ before pregnancy (Alice et al., 2012). This discrepancy may be the difference in economic back ground of the study participants in the studies.

In general, $33.9 \%$ of the respondents were found to have good practice depending up on questions offered to them to assess practice of mothers' nutrition during their pregnancy. This figure is lower than the study conducted in Malawi that $(57 \%)$ of the pregnant women had good practices on nutrition and food groups in pregnancy (Naomi, 2010). This low nutritional practice may be due to low nutritional knowledge of the pregnant mother and family member during pregnancy, low income, relatively high family size, lack of information about nutrition during pregnancy and low educational status of the study participants in this study.

\section{Factors Affecting Practices of Mothers On Maternal Nutrition During Pregnancy}

The finding of this study identified that family size have strong statistical association with nutrition practices of mothers during pregnancy $(P<0.001)$. Relative to the pregnant women with family size 1-2, women with family size of $\geq 5$ had 0.039 less likely nutrition practice during pregnancy (AOR $=0.039$, 95\% Cl: $0.010-0.151)$ which is similar to the study conducted in Accra, Ghana in household size was predictor of nutrient intake practice in pregnant women (Alice et al., 2012).

In addition the finding of this study revealed that information about nutrition during pregnancy have strong statistical association with practices of mothers on nutrition $(P<0.001)$.Women who had information about nutrition during pregnancy had 6.3
Sci. Technol. Arts Res. J., July-Sep 2013, 2(3): 105-113

more likely good nutrition practice than women who had no information during pregnancy $(A O R=6.264$, 95\% Cl: 3.487-11.254).

The most significant predictor for good nutritional practices was information about nutrition, women occupation and family size. This result supported by the fact that good knowledge about basic nutrients and adequate well balanced diet usually resulting in positive dietary practices which are important determinants of optimum health from conception until death (Painter et al., 2003).

\section{CONCLUSION}

Based on the findings of the present study, it can be concluded that most pregnant mothers in the study area were illiterate, had low income, house wife and their husband engaged in farming. The pregnant mothers' access to nutritional information in the study area was also relatively low.

This finding also showed only less than half of the respondents $33.9 \%$ were found to have good nutritional practices during their pregnancy. Some pregnant mothers in the study (35.8\%) had practiced avoiding food during their pregnancy due to religion, culture and thinking that the food items make the baby big and more than half of the respondent had diet frequency of meal one to two per day. There was also significant positive relation between family size, nutrition information during pregnancy and mothers' occupation and nutrition practices of mother during pregnancy that this research identified. Hence, nutrition intervention such as nutrition education in different villages, health centers, health posts and women organizations should be given for the community particularly for the pregnant mothers concerning nutrition during pregnancy in the study area.

\section{REFERENCES}

AED LINKAGES, (2004). Maternal Nutrition: Issues and Interventions; computer based slide presentation, by the Bureau for Global Health of the United States Agency for International Development (USAID), Updated August, 2004.

Alice, K., Christina A. and Richard A. (2012). Detary Practices and Nutrient Intakes of Pregnant Women in Accra, Ghana; Current Research Journal Biological Sciences 4(4): 358-365.

Barker, D.J.P., Godfrey, K.M., Gluckman, P.D., Harding, J.E., Owens, J.A and Robinson, J.S. (1993). Maternal Nutrition from pre-pregnancy to lactation. The Lancet 341 (8850): 938-941.

Huffman, S., Zehner, E., Harvey, P., Martin, L., Piwoz, E., Ndure, K., Combest, C., Mwadime, R., and Quinn, V., (2001). "Essential Health Sector Actions to Improve Maternal Nutrition in Africa". Pp. 1-56. 


\section{Gemeda Daba et al.,}

IYCN, (2011). Infant \& Young Child Nutrition Project; Literature Review Prepared for the Message and Materials Development Workshop produced through support provided by the United States Agency for International Development (USAID), Addis Ababa, Ethiopia January 2011.

Luigi, R., Orbitello,, B., Perini, L., Pera, V., Ciano, R. and Balestrieri M., (2005). Effects of pregnancy on eating attitudes and disorders. A prospective study Journal of Psychosomatic Research 59 (3): 175 -179.

Maynord, K., Westenbey, L. (2003). Aboriginal teenage pregnancies compared with non aboriginal in south Australia; Journal of obestet. Gynecolology 42(2):187.

Mora, J., and Nestel, P. (2000). Improving prenatal nutrition in developing countries: strategies, prospects, and challengers. American Journal of Clinical Nutrition 71 (5): 1353S-1363S.

Nagiebs, S. (2003). Nutrition during maternity cycle; Review article, University of Assiut, Faculty of Nursing. Pp.18-22.

Naomi, M. (2010). Investigating health and nutrition messages given to pregnant women at bwaila hospital in Lilongwe; master thesis;food, nutrition and health , August 2010. Akershus University College; Faculties of Health, Nutrition and Management.

Nicholson, W., Setse, R., Hill-Briggs, F., Cooper, L., Strobino, D. and Powe N. (2006). Depressive Symptoms and Health-Related Quality of Life in Early pregnancy. Journal of Obstetrics and Gynecology 107(4): 798-806.

Otchet, F., Carey, M. and Adam, L. (1999). General health and psychological symptom status in pregnancy and the puerperium: what is normal? Journal of Obstetrics and Gynecology 94 (6): 935-941.
Sci. Technol. Arts Res. J., July-Sep 2013, 2(3): 105-113

Painter J., Rah J., Lee Y. (2003). Comparison of international food guide pictorial representation. Journal of the American Dietetic Association 102(4): 483- 489.

Rao, A., S. Sahoo and P. Basumati, (2006). A study of nutritional status of pregnant women of some villages in Balasore district, Orissa. The Journal of Human Ecology 20(3): 227-232.

Tinker, A., and Koblinsky, M. (1994). Making motherhood safe. Washington, DC: World Bank,World Bank discussion paper; Pp. 202.

Tsegaye Demissie, Muroki, N.M and Wambui KogiMakau, (1996). Food aversions and cravings during pregnancy: Prevalence and significance for maternal nutrition in Ethiopia, Department of Nutrition and Food Science, in Addis Ababa, Ethiopia.

UNICEF, (2009). Maternal and Newborn Health in Nigeria: Developing Strategies to Accelerate Progress. The State of World's Children; Pp. 19-22.

Villar, J., Merialdi, M., Gülmezoglu, A. (2003). Nutritional interventions during pregnancy for the prevention or treatment of maternal morbidity and preterm delivery: an overview of randomized controlled trials. Journal of Nutrition 133 (5 suppl 2):1606S-1625S.

WHO, (1997). Coverage of maternity care: a listing of available information. Geneva: World Health Organization; WHO/RHT/MSM/96.28.

World Bank, (2006). Repositioning Nutrition as central to development: A strategy for large scale action, The International Bank for Reconstruction and Development, World Bank, Washington DC.

Wu, G., Fuller, W. and Cudd, T. (2004). Maternal Nutrition and Fetal Development. Journal of Nutrition 134: 2169-2172. 